\title{
Biopolymer phytagel-derived porous nanocarbon as efficient electrode material for high-performance symmetric solid-state supercapacitors
}

Karuppasamy, K.; Kadirvelayutham, Prasanna; llango, P. Robert ; Vikraman, Dhanasekaran ; Bose, Ranjith ; Alfantazi, Akram ; Kim, Hyun-Seok

Published in:

Journal of Industrial and Engineering Chemistry

Link to article, DOI:

10.1016/j.jiec.2019.08.003

Publication date:

2019

Document Version

Peer reviewed version

Link back to DTU Orbit

Citation (APA):

Karuppasamy, K., Kadirvelayutham, P., Ilango, P. R., Vikraman, D., Bose, R., Alfantazi, A., \& Kim, H-S. (2019). Biopolymer phytagel-derived porous nanocarbon as efficient electrode material for high-performance symmetric solid-state supercapacitors. Journal of Industrial and Engineering Chemistry, 80, 258-264.

https://doi.org/10.1016/j.jiec.2019.08.003

\section{General rights}

Copyright and moral rights for the publications made accessible in the public portal are retained by the authors and/or other copyright owners and it is a condition of accessing publications that users recognise and abide by the legal requirements associated with these rights.

- Users may download and print one copy of any publication from the public portal for the purpose of private study or research.

- You may not further distribute the material or use it for any profit-making activity or commercial gain

- You may freely distribute the URL identifying the publication in the public portal 


\title{
Biopolymer phytagel-derived porous nanocarbon as efficient electrode material for high-performance symmetric solid-state supercapacitors
}

\author{
K. Karuppasamy ${ }^{1}$, K. Prasanna ${ }^{2}$, P. Robert Ilango ${ }^{3}$, Dhanasekaran Vikraman ${ }^{1}$, Ranjith Bose ${ }^{4}$, \\ Akram Alfantazi ${ }^{4}$, Hyun-Seok Kim ${ }^{1 *}$ \\ ${ }^{I}$ Division of Electronics and Electrical Engineering, Dongguk University-Seoul, Seoul 04620, \\ Republic of Korea \\ ${ }^{2}$ Department of Energy Conversion and Storage, Technical University of Denmark, \\ Frederiksborgvej 399, P.O. Box 49, DK-4000 Roskilde, Denmark \\ ${ }^{3}$ Department of Materials Science and Engineering, National Tsing Hua University, Hsinchu, \\ Republic of China \\ ${ }^{4}$ Department of Chemical Engineering, Khalifa University, Abu Dhabi 127788, United Arab \\ Emirates \\ *Corresponding author; e-mail: hyunseokk@dongguk.edu
}

\begin{abstract}
In the present work, a porous nano-carbon (PNC) based electrode materials were successfully derived from the natural biopolymer phytagel via a facile hydrothermal and combustion process. The carbon phase structure of the PNC electrode was confirmed using different spectroscopy, microscopy and $\mathrm{N}_{2}$ adsorption-desorption analyses. The surface morphology investigation showed a distinct shape and size for the PNC that demonstrated its porous nature. The electrochemical performance of PNC was completely reliant on the calcination temperature $\left(800^{\circ} \mathrm{C}\right)$ and it delivered the maximum capacitance of $122 \mathrm{~F} \mathrm{~g}^{-1}$ at 0.25 $\mathrm{Ag}^{-1}$. An AC impedance and cyclic voltammetry analyses proved the intrinsic electrochemical behavior by their cycling. Besides, the fabricated symmetric solid-state supercapacitor displayed an outstanding cycle durability with a stable capacitance retention of $85.8 \%$ over 8,000 cycles, suggesting favorable prospects for its use as an active candidate for symmetric solid-state supercapacitor applications.
\end{abstract}

Keywords: biopolymer, hydrothermal, porous carbon, electrochemical properties. 


\section{Introduction}

Supercapacitors (SCs) are alternative energy storage systems that can offer long life times $\left(>10^{5}\right)$, fast charge-discharge process, outstanding safety, and high power densities $\left(10 \mathrm{~kW} \mathrm{~kg}^{-1}\right)$ and have played a decisive protagonist in several areas such as in the evolution of hybrid electric vehicles, automobiles and memory back-up etc. [1-5]. Nevertheless, their forthcoming usage has been restricted through their low energy density $[6,7]$. To resolve this dispute, several efforts have been made to build high-performance SCs with high energy densities using various materials include transition metal oxides, porous carbon, and conducting polymers [8-10]. In general, carbon based material are being used as alternative electrode materials for supercapacitor applications owing to their low cost, high surface areas, and excellent thermoelectrical conductivity [11-13]. Moreover, carbon derivatives such as graphene, carbon fibers, carbon nanotubes, and activated carbon have also been considered as active electrode materials for high-performance SCs. Among them, porous carbon offers better intrinsic electrochemical properties than those of other carbon allotropes [14-20].

Nowadays, numerous researches have been keen to improve the energy density of carbon compounds by combining them with conducting polymers and oxides of transition metal ions and the resulting materials have been employed as anode materials of solid-state battery-type asymmetric SCs (ASCs) [21-23]. However, unfortunately, the cycling and electrochemical performances of such devices were very poor, which did not allow the carbon SCs to grow in popularity. The major drawback that limits the development of carbon-based SCs are the capital cost and limited resources because most carbon materials are obtained from petroleum-based hydrocarbons $[24,25]$. In this context, biomass-derived carbon materials are receiving growing demand from the scientific community for the construction of high-performance carbon based 
SCs due to their abundance in earth and because they are ecofriendly and cheap [7, 26]. So far, many biomass materials such as banana peel waste [26, 27], celery stem [28], lignin [29], onion tissue [30], lentinus edoes [31], chicken feathers [32], and chitosan [33] have been converted to carbon for use in supercapacitors and their performances have been investigated. In addition, a general route to improve the surface area is through activation, which has shown to lead to excellent charge discharge rates [34]. For example, $\mathrm{KOH}$-activated bamboo sticks and $\mathrm{NaOH}-$ activated Eichhornia crassipes demonstrated improved performance in terms of cycling stability, energy density, and specific capacitance $[35,36]$. Herein, we aimed to prepare a porous nanocarbon (PNC) from biopolymer phytagel using a simple hydrothermal strategy. The reason for choosing phytagel as a potential candidate for carbon source may attributed to the following facts: (a) It is one of the naturally occurring carbohydrate biopolymer with admirable assets for instance cost effective, eco-friendly nature, nonhazardous, thermal resistance, and easy chemical modification (b) further, it comprises of chemically reactive - $\mathrm{OH}$ and $-\mathrm{COOH}$ moieties, which deliver easily available sites for functionalization $[37,38]$. The phase and morphology of the PNC derived from phytagel and its electrochemical features such as specific capacitance and charge discharge behavior were investigated and have been discussed herein in detail.

\section{Experimental}

The raw phytagel $(1000 \mathrm{~kg} / \mathrm{mol}$; low acylation degree), orthophosphoric acid $(85 \mathrm{wt} \%$, $\mathrm{M}_{\mathrm{w}}$ : 98.0), and potassium hydroxide $\left(\mathrm{M}_{\mathrm{w}}: 56.11\right)$ were purchased from Sigma Aldrich. The PNC was derived from the biopolymer phytagel powder according to a procedure reported elsewhere $[39,40]$. Prior to the purification step, the phytagel was kept in vacuum for $12 \mathrm{~h}$ at $50^{\circ} \mathrm{C}$.

$0.5 \mathrm{~g}$ of the dried phytagel powder was hydrolyzed using $40 \mathrm{~mL}$ of a dilute orthophosphoric acid solution $\left(\mathrm{H}_{3} \mathrm{PO}_{4}\right)$ under mild stirring and gently heating at $50{ }^{\circ} \mathrm{C}$ for one 
day. The possible activation process of phytagel with $\mathrm{H}_{3} \mathrm{PO}_{4}$ is displayed in Figure 1. Then, the tacky pasty solution was reassigned into a $40 \mathrm{~mL}$ Teflon-sealed autoclave and subjected to hydrothermal treatment at $160^{\circ} \mathrm{C}$ for $16 \mathrm{~h}$ in an oven. Subsequently, the autoclave was endorsed to chill naturally. The colloidal product obtained subsequently was rinsed with double DI water and dried at $60^{\circ} \mathrm{C}$ overnight.

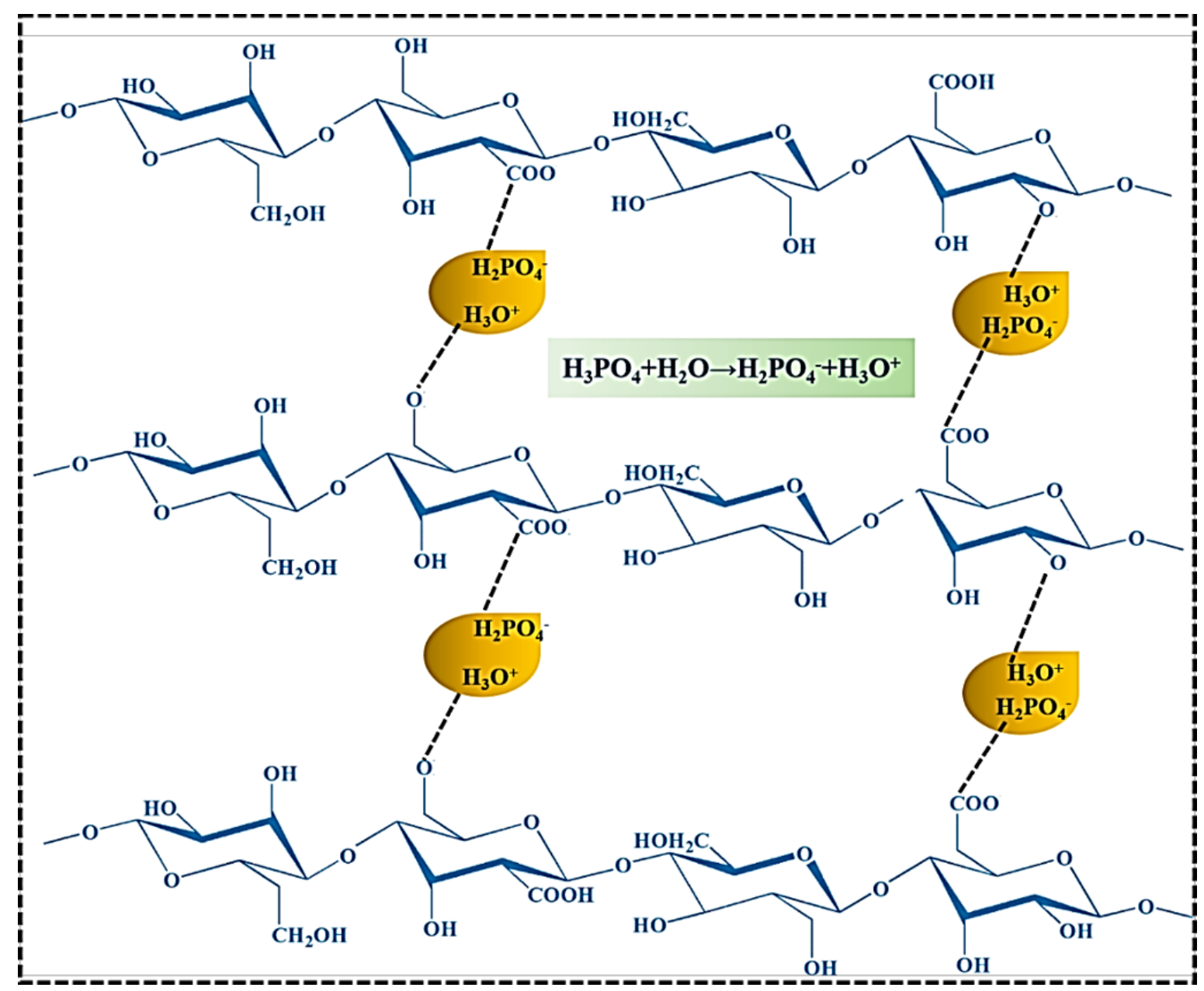

Figure 1: Schematic mechanism of activation process of phytagel using orthophosphoric acid

Dried samples were then treated with $\mathrm{KOH}$ in the stoichiometric ratio of $1: 1.5$ and the mixed powders was moved to a porcelain crucible that was then kept in a high temperature tube furnace. The furnace temperature was raised into $800^{\circ} \mathrm{C}$ at $10^{\circ} \mathrm{C} \mathrm{min}^{-1}$ heating rate in an argon 
atmosphere and seized at $800^{\circ} \mathrm{C}$ for $2 \mathrm{~h}$. Then, the furnace was naturally allowed to settle down to ambient temperature. The solid product gotten was treated with the mixtures of $\mathrm{HCl} /$ water and water/ethanol solutions several times. In order to avoid impurities the washed PNC powders were dried at $80{ }^{\circ} \mathrm{C}$ for $12 \mathrm{~h}$ in an oven to obtain a fine pure powder. The synthesis is schematically exemplified in Figure 2.

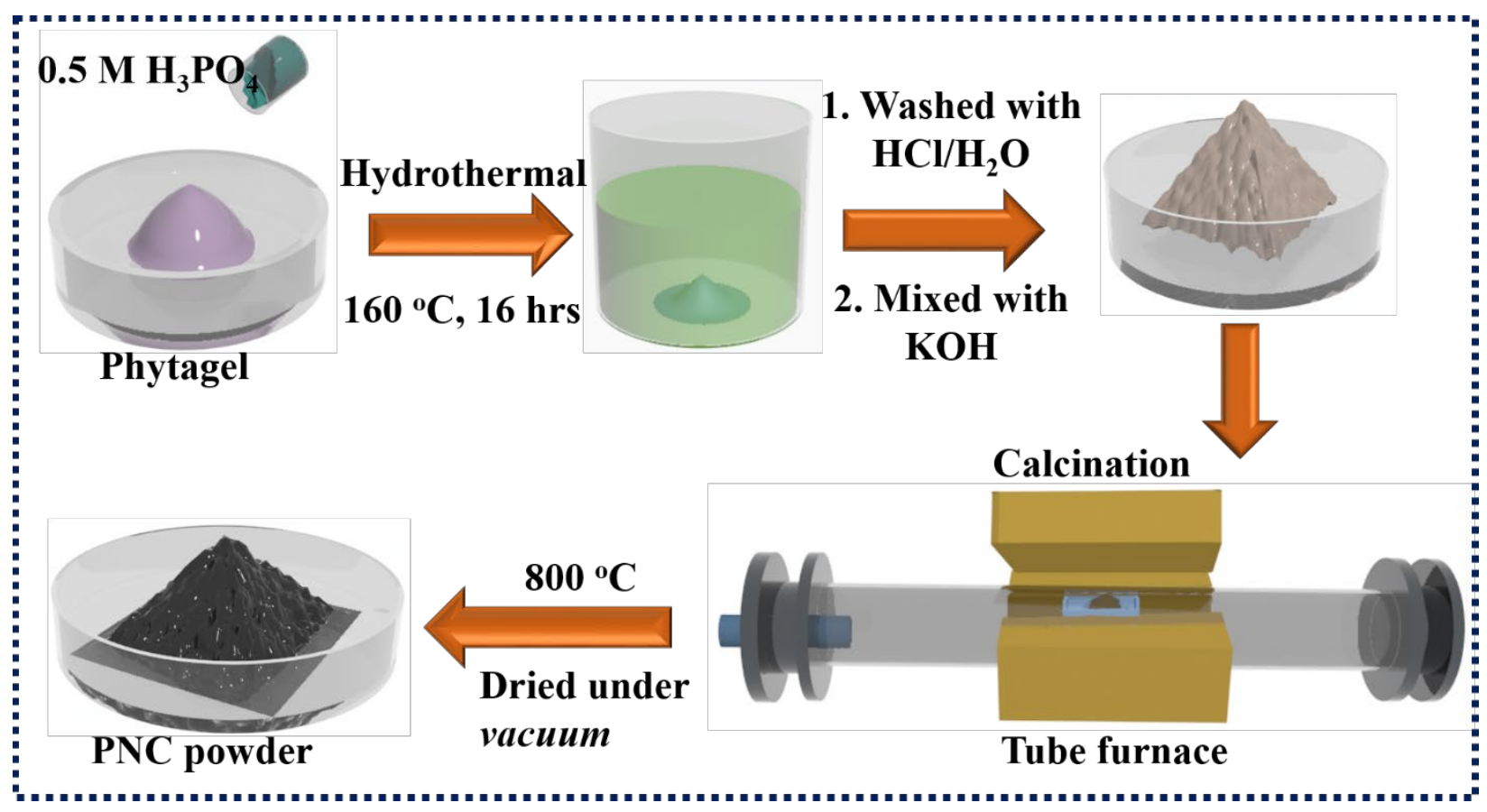

Figure 2: Schematic synthesis of PNC powder using hydrothermal and combustion methods

The working-cum-counter active electrodes were prepared in this following fashion: A mixture with $80 \%$ of synthesized PNC, $10 \%$ of Super $\mathrm{P}$, and $10 \%$ PVdF (poly vinylidenefluoride) content were dispersed in an N-methyl pyrrolidone solvent and allowed to form a coagulated paste, which was used to coat a current collector Ni Foam that was then, placed beneath vacuum at $120{ }^{\circ} \mathrm{C}$ for overnight and used as the positive and negative electrodes. A hybrid symmetric cell was fabricated using the abovementioned fabricated electrodes and a 
Whatman filter paper separator (soaked in $6 \mathrm{M} \mathrm{KOH}$ ). The active masses of the electrodes were $0.055 \mathrm{~g}$ and $0.049 \mathrm{~g}$.

The structural behaviors of the synthesized PNC were examined through Raman spectroscopy (FT-Raman), X-ray diffraction analysis (XRD), transmission electron microscopy (HR-TEM), thermogravimetric analysis (TGA), and field-emission scanning electron microscopy (FE-SEM). The XRD analysis was conducted through Rigaku X-ray diffractometer (D-Max $2500)$ at $40 \mathrm{kV}$ and $30 \mathrm{~mA}$ reflux at $2^{\circ} / \mathrm{min}$ via $\mathrm{Cu}-\mathrm{K} \alpha(\lambda=1.540 \AA)$ with $2 \theta=10-80^{\circ}$. Raman analysis was performed utilizing a Renishaw Micro-Raman spectrometer analyzer by means of a He-Ne source in the range $2000-1000 \mathrm{~cm}^{-1}$. TGA measurements were performed via a thermobalance (Thermo Plus2/TG-DTA, Rigaku Co) that were recorded by a computer from the temperature range from 35 to $800^{\circ} \mathrm{C}$ at $10^{\circ} \mathrm{C} / \mathrm{min}$. The surface morphology of the PNC powder was perceived using FE-SEM (JSM-6700F) and HR-TEM (JEM-2010F). Brunauer-EmmettTeller measurements of the PNC were carried out in a liquid nitrogen atmosphere using ASAP 2010 analyzer (Micromeritics, USA). Electrochemical measurements were performed via cyclic voltammetry (CV), charge-discharge (GCD), and electrochemical impedance spectral (EIS) analyses. Electrochemical analyses were conducted by means of the VersaSTAT3 electrochemical workstation (Princeton, USA). The CV curves were analyzed in the potential range -1 to $0 \mathrm{~V}$ at diverse scan rates $\left(5-50 \mathrm{mVs}^{-1}\right)$. Impedance analysis was carried out in the frequency range from $0.1 \mathrm{~Hz}$ to $1 \mathrm{MHz}$ with a signal amplitude of $10 \mathrm{mV}$. GCD curves were recorded at various current rates $\left(0.25-8 \mathrm{Ag}^{-1}\right)$.

\section{Results and Discussions}

\subsection{Physicochemical analyses}


The crystallinity and phase purity of the PNC derived from the phytagel biopolymer was estimated through the X-ray diffraction pattern obtained, displayed in Figure 3(a). The figure shows two predominant broad peaks at $2 \theta=21.5^{\circ}$ and $43.2^{\circ}$, which are related to the (002) and (100) reflection planes of carbon, respectively. Both peaks showed a shift to lower $2 \theta$ values compared to those noted for graphitic carbon derived from other bio-resources [41, 42], owing to the introduction of $\mathrm{C}-\mathrm{O}$ bonds initiating slackening and distortions in the $s p^{2}$ carbon and increase in the interlayer distance between adjacent graphitic layers within the structure. The broadness of the diffraction peaks further clearly confirmed the amorphous nature of the prepared sample, which was in agreement with results reported earlier [36]. The Raman analysis was performed from 2000 to $800 \mathrm{~cm}^{-1}$, as shown in Figure 3(b). Two dominant peaks were observed at 1320 and $1590 \mathrm{~cm}^{-1}$, owing to the $A_{1 g}$ and $E_{2 g}$ modes of $D$ and $G$ bands, respectively. The perfection and tangled structure of graphitic carbon was evaluated through the Raman intensity ratio $I_{D} / I_{G}$, and it was found to be 1.11 . The obtained high $I_{D} / I_{G}$ value undoubtedly indicated that the synthesized graphitic carbon contained of a scarce layers of graphitic sheets with minor flaws include empty sites, topological imperfections and, dangling bonds which ought to be the presence of O-atoms in the carbon lattice structure.

The TGA thermogram of graphitic nanocarbon is shown in Figure 3(c). The prepared sample exhibited two thermal degradation events: an initial water loss up to $220{ }^{\circ} \mathrm{C}$ and thermal decomposition $\left(T_{m}\right)$ at temperatures of $340-380^{\circ} \mathrm{C}$. The second thermal event, which occurred at around $360^{\circ} \mathrm{C}$, might be mostly ascribed to the decomposition of $\mathrm{C}-\mathrm{H}, \mathrm{O}-\mathrm{H}, \mathrm{C}-\mathrm{C}, \mathrm{C}=\mathrm{O}$, and $\mathrm{C}-$ O bonds during the dilapidation of the biopolymer phytagel polysaccharide chain. A greater amount of graphitic carbon residue observed at $440{ }^{\circ} \mathrm{C}(28.0 \%)$ might represent the percentage of carbon particles. The observed phenomenon is in accordance with earlier reports and also 
confirmed the formation of carbon particles at elevated temperatures. Figure 3(d) shows the $\mathrm{N}_{2}$ adsorption-desorption isotherm acquired for the synthesized nanocarbon. It is evident from the isotherm that the synthesized carbon consisted of both mesopores and macropores, i.e. both type II and type IV curves were present at low and high vapor pressures. Further, two different insulated capillary condensation of hysteresis ladders observed in the isotherm curve at $\mathrm{p} / \mathrm{p}_{0}$ $<0.92$ and $>0.92$ confirmed the meso-macroporous structure of the synthesized samples. The surface area and pore volume were recognized to be $0.08021 \mathrm{~cm}^{3} \mathrm{~g}^{-1}$ and $930 \mathrm{~m}^{2} \mathrm{~g}^{-1}$, which confirmed the high porosity of the synthesized PNC.
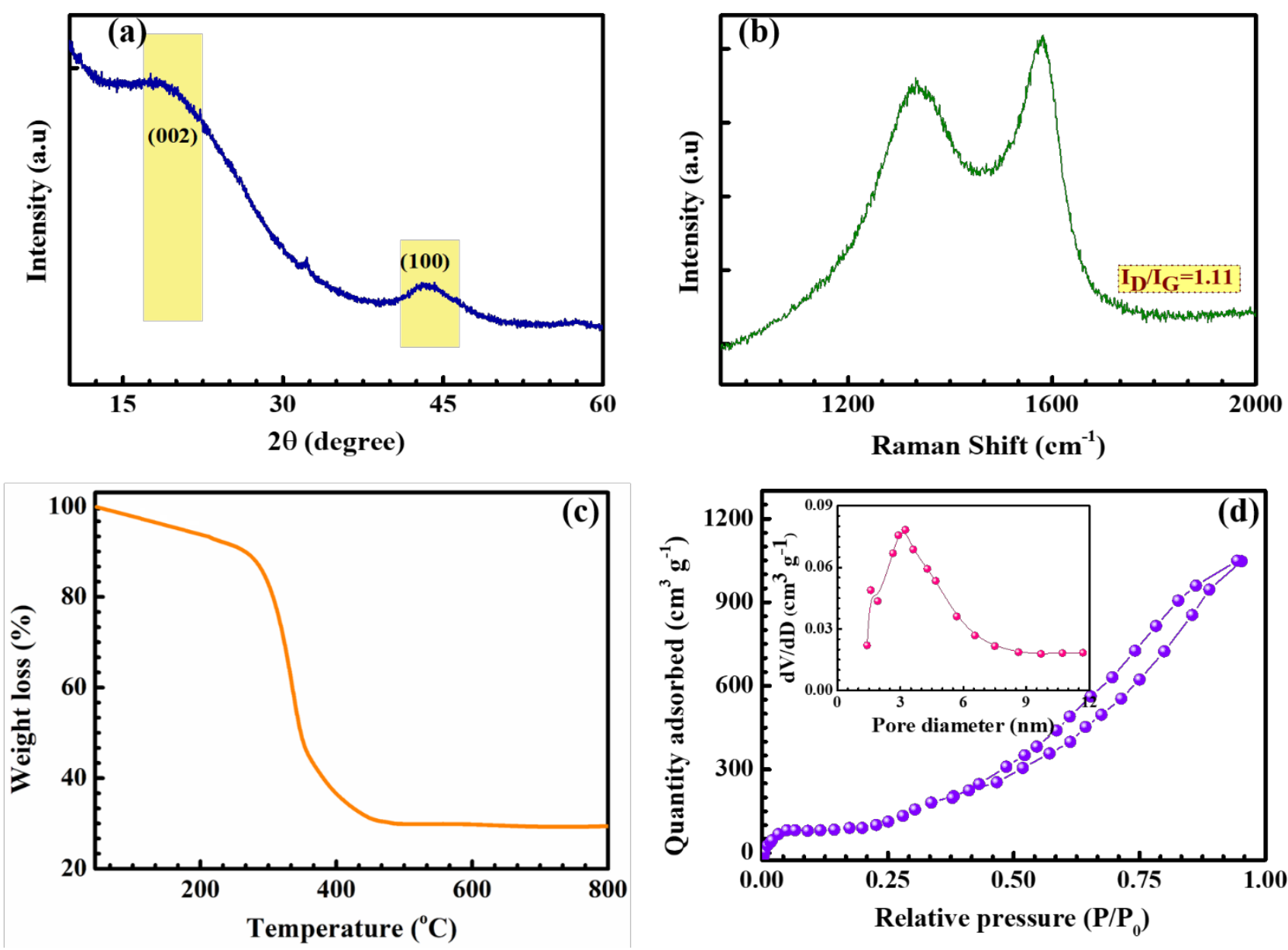
Figure 3: (a) XRD pattern, (b) Raman spectrum, (c) TGA thermogram and (d) $\mathrm{N}_{2}$ adsorptiondesorption isotherm obtained for PNC.

The morphology and particle size of the synthesized PNC were perceived through FESEM and HR-TEM analyses and the ensuing images are depicted in Figure 4(a-d). The PNC particles consisted of a three-dimensional interconnected polyhedron network with a distinctly smooth morphology, as shown in Figure 4(a). The size distribution of the PNC particles encompassed the range $65-75 \mathrm{~nm}$. Figure 4(b) shows a high-magnification image that exhibits more opaque and larger pores over the microporous network structure. To confirm the results acquired by SEM analysis, HR-TEM analysis was employed, as displayed in Figure 4(c, d). Cautious inspection of the images clearly indicates homogeneous distribution of the PNC particles and an ordered polyhedral shape. The average size of each polyhedron was found in the range of $75-85 \mathrm{~nm}$, which is in close agreement with results derived by SEM analysis. 

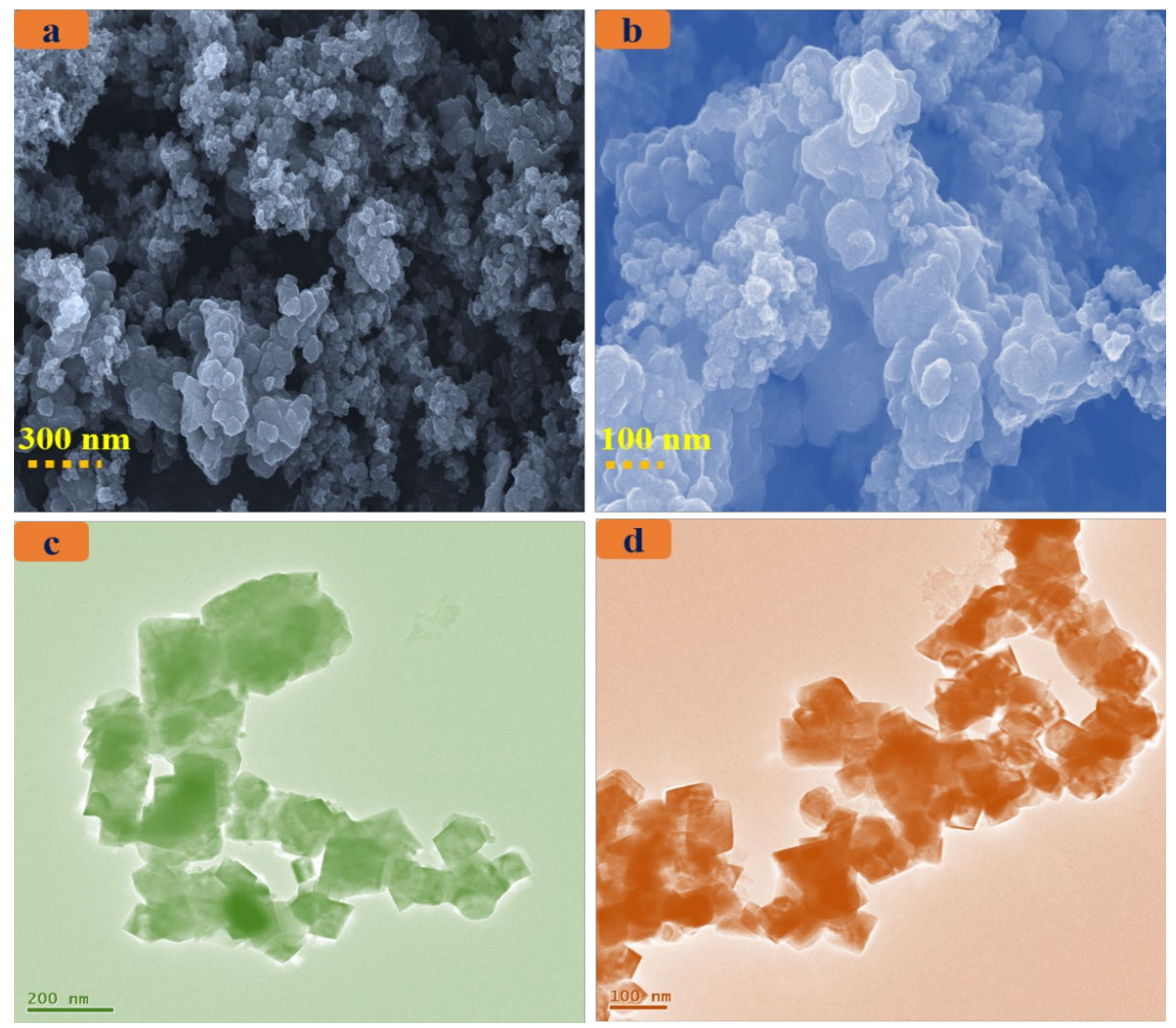

Figure 4: (a, b) FE-SEM of PNC powder at high and low magnifications, (c,d) HR-TEM images of PNC at different magnifications.

\subsection{Supercapacitive performance}

To validate the electrochemical behavior along with the feasibility of using PNC electrodes in SCs, a symmetric cell was assembled using the synthesized PNC as symmetric electrodes i.e., working-cum-counter electrodes, and a $\mathrm{KOH}$-soaked Whatman filter paper as separator electrolyte. The capacitive performance of the symmetric cell was assessed using cyclic voltammetry and the ensuing curve is provided in Figure 5(a) for the fixed potential window of -1 to $0 \mathrm{~V}$. The shape of the $\mathrm{CV}$ profile was almost quasi-rectangular without any redox peak, which implied that the capacitance is stored by non-faradaic reactions on the 
electrode-electrolyte interfaces, which is recognized as double layer capacitance. It is recognized that carbon-based electrodes exhibit electric double layer behavior, and so it is genuine to accept that the double layer capacitive effect arose from the PNC working electrode [43]. In general, the specific capacitance is assessed by integral part of area under the curve; in the present investigation, an increasing trend was noted for the capacitance with increase in cycles, as displayed in Figure 5(b). The CV curves obtained for the PNC cell at various scan rates are depicted in Figure 5(c). No significant changes were found in the voltammograms even at high scan rates, demonstrating the firm charge-discharge behavior. Furthermore, the intercalating and de-intercalating current enhanced with increase in the scan rate and did not follow an undeviating fashion, as depicted in Figure 5(d). Therefore, the electrochemical chargedischarge process was facile over the electrolyte-electrode interfaces and was further strengthened by galvanostatic charge-discharge processes, as discussed later.

In order to utilize the synthesized PNC electrodes for practical SC applications, the solidstate symmetric SC cells were subjected to galvanostatic charge-discharge processes as displayed in Figure 6(a). The specific capacitance $C \mathrm{sp}$ of the cells were evaluated using the following expression:

$$
C_{s p}=2 \times \frac{\Delta t \times I}{\Delta V \times m}
$$

where $\Delta \mathrm{t}$ and $\Delta \mathrm{V}$ represent the discharge time and potential window range respectively; $m$ indicates the mass of the active electrode sample, and I is the discharge current. As depicted in Figure 6(b), the calculated $C$ sp of the symmetric cell based on the above equation was $122 \mathrm{Fg}^{-1}$ at $0.25 \mathrm{~A} \mathrm{~g} \mathrm{~g}^{-1}$, which was knowingly greater than recently reported for biopolymer-derived carbon-based SC devices [44-48]. The previously reported porous carbon capacitance values are displayed in Table 1 which were extracted from bio-waste materials. 
Furthermore, the energy density (ED) and power density (PD) of the PNC-based symmetric device was also determined through the resulting two equations given below:

$$
\begin{aligned}
& \mathrm{ED}=\left(\Delta V^{2} \times C_{s p} / 2\right) / 3.6 \\
& \mathrm{PD}=(E D * 3600 / \Delta t)
\end{aligned}
$$

The calculated ED and PD values were plotted in a Ragone plot exposed in Figure 6(c). The SC symmetric cell offered of a high ED value of 14.38 and $5.62 \mathrm{Wh} \mathrm{kg}^{-1}$ at a PD of 360 and $980 \mathrm{Wkg}^{-1}$ respectively. The measured ED and PD values of the present system was superior compared to other recently reported biopolymer-derived carbon-based SC cells. As represented in Figure 6(d), the outstanding long-term stability of the PNC-based symmetric SC device was verified and the device maintained $85.8 \%$ of the $C_{\text {sp }}$ even after the 8000 cycles, which suggests that the prepared PNC can be a promising candidate for practical solid-state energy storage devices.

\begin{tabular}{|c|c|c|c|c|}
\hline Electrode & Electrolyte & $\begin{array}{l}\text { Specific } \\
\text { capacitance }\end{array}$ & $\begin{array}{l}\text { Capacitance } \\
\text { retention (\%) } \\
\text { for minimum } \\
1000 \text { cycles }\end{array}$ & Ref \\
\hline $\begin{array}{l}\text { Porous nanocarbon derived from } \\
\text { Phytagel }\end{array}$ & 6М КОН & $122 \mathrm{Fg}^{-1}$ & $\begin{array}{l}85.8(8000 \\
\text { cycles })\end{array}$ & $\begin{array}{l}\text { This } \\
\text { work }\end{array}$ \\
\hline PAN based carbon nanofiber paper & $\begin{array}{l}\mathrm{Et}_{4} \mathrm{NBF}_{4} \text { in } \\
\text { acetonitrile }\end{array}$ & $108 \mathrm{Fg}^{-1}$ & 64.8 & [49] \\
\hline Sodium alginate based carbon & $1 \mathrm{M} \mathrm{H}_{2} \mathrm{SO}_{4}$ & $198 \mathrm{Fg}^{-1}$ & 89.98 & {$[50]$} \\
\hline Seaweed carbon & $1 \mathrm{M} \mathrm{H}_{2} \mathrm{SO}_{4}$ & $180 \mathrm{Fg}^{-1}$ & -- & [51] \\
\hline Activated carbon & $\mathrm{Li}_{2} \mathrm{SO}_{4}$ & $102 \mathrm{Fg}^{-1}$ & 89 & {$[52]$} \\
\hline
\end{tabular}

Table 1: Electrochemical performance of carbon electrodes resulting from biomaterials 


\begin{tabular}{|c|c|c|c|c|}
\hline $\begin{array}{l}\text { porous carbon nanofiber derived } \\
\text { from polymethylhydrosiloxane } \\
\text { (PMHS)/polyacrylonitrile (PAN) }\end{array}$ & $6 \mathrm{M} \mathrm{KOH}$ & $126 \mathrm{Fg}^{-1}$ & --- & [53] \\
\hline Cellular CNT films & $\begin{array}{l}10 \mathrm{wt} \% \mathrm{H}_{3} \mathrm{PO}_{4} / \\
\text { polyvinyl alcohol } \\
\text { (PVA) gel } \\
\text { electrolyte }\end{array}$ & $72.9 \mathrm{Fg}^{-1}$ & 82.85 & [54] \\
\hline CNT & $\begin{array}{l}1-\mathrm{M} \mathrm{Na}_{2} \mathrm{SO}_{4} \\
\text { solution }\end{array}$ & $\begin{array}{l}120 \mathrm{Fg}^{-1} \text { for } \\
\mathrm{CNT}\end{array}$ & --- & [55] \\
\hline $\begin{array}{l}\text { Carbon black }+ \text { reduced graphene } \\
\text { oxide }\end{array}$ & $\mathrm{PVA}+\mathrm{H}_{3} \mathrm{PO}_{4}$ & $115 \mathrm{Fg}^{-1}$ & 88 & [56] \\
\hline CNT growth on stainless steel & $\begin{array}{l}\text { poly-ethylene } \\
\text { glycol diglycidal } \\
\text { ether (PEDGE) - } \\
\text { ionic liquid (IL) }\end{array}$ & $120 \mathrm{mFcm}^{-3}$ & --- & [57] \\
\hline Graphene oxide & $6 \mathrm{M} \mathrm{KOH}$ & $94.4 \mathrm{Fg}^{-1}$ & 51.3 & [58] \\
\hline Porous carbon nanoparticles & $5 \mathrm{M} \mathrm{KOH}$ & $343 \mathrm{Fg}^{-1}$ & 95 & [59] \\
\hline $\begin{array}{l}\text { Heteroatom doped carbon derived } \\
\text { from human waste }\end{array}$ & $6 \mathrm{M} \mathrm{KOH}$ & $166 \mathrm{Fg}^{-1}$ & 98.3 & [60] \\
\hline Mesoporous activated carbon & $6 \mathrm{M} \mathrm{KOH}$ & $222 \mathrm{Fg}^{-1}$ & 94 & [61] \\
\hline Hemp derived activated carbon & $\begin{array}{l}1.8 \mathrm{M} \\
\mathrm{TEMABF}_{4} / \mathrm{PC}\end{array}$ & $160 \mathrm{Fg}^{-1}$ & 83.9 & [62] \\
\hline Activated carbon & $\mathrm{PVA}+\mathrm{H}_{3} \mathrm{PO}_{4}$ & $188 \mathrm{Fg}^{-1}$ & 99 & [63] \\
\hline Soybean derived carbon & $1 \mathrm{~mol} \mathrm{~L}^{-1} \mathrm{H}_{2} \mathrm{SO}_{4}$ & $150 \mathrm{Fcm}^{-3}$ & $>60$ & [64] \\
\hline N-containing chitosan doped carbon & $1 \mathrm{M} \mathrm{H}_{2} \mathrm{SO}_{4}$ & $19.5 \mu \mathrm{Fcm}^{-2}$ & 83 & [65] \\
\hline $\begin{array}{l}\text { Hierarchically porous carbon } \\
\text { microspheres-PANI (chitin) }\end{array}$ & $1 \mathrm{M} \mathrm{H}_{2} \mathrm{SO}_{4}$ & $76 \mathrm{Fg}^{-1}$ & 90.6 & [66] \\
\hline $\begin{array}{l}\text { Microporous activated carbon } \\
\text { synthesized from waste compact } \\
\text { discs }\end{array}$ & $\mathrm{EMImBF}_{4}$ & $51 \mathrm{Fg}^{-1}$ & 80 & [16] \\
\hline $\begin{array}{l}\text { graphene-like carbon nanosheets } \\
\text { derived from cucumber }\end{array}$ & $6 \mathrm{M} \mathrm{KOH}$ & $143 \mathrm{Fg}^{-1}$ & 97 & [15] \\
\hline $\begin{array}{l}\text { hierarchical porous activated carbon } \\
\text { derived from waste cumin plant }\end{array}$ & $1 \mathrm{M} \mathrm{H}_{2} \mathrm{SO}_{4}$ & $155 \mathrm{Fg}^{-1}$ & 96.9 & [17] \\
\hline $\begin{array}{l}\text { Waste-derived Microporous carbon- } \\
\text { based materials }\end{array}$ & $6 \mathrm{M} \mathrm{KOH}$ & $512 \mathrm{Fg}^{-1}$ & $>90$ & [18] \\
\hline Nanoporous & $6 \mathrm{M} \mathrm{KOH}$ & $330 \mathrm{Fg}^{-1}$ & 85.6 & [19] \\
\hline
\end{tabular}


pyropolymer nanosheets derived from citreae peels

Hierarchical porous carbons derived from waste plastic bags

\begin{tabular}{|l|l|l|l|} 
& & & \\
$\mathrm{EMImBF}_{4}$ & $100 \mathrm{Fg}^{-1}$ & 97.1 & {$[20]$} \\
\hline
\end{tabular}
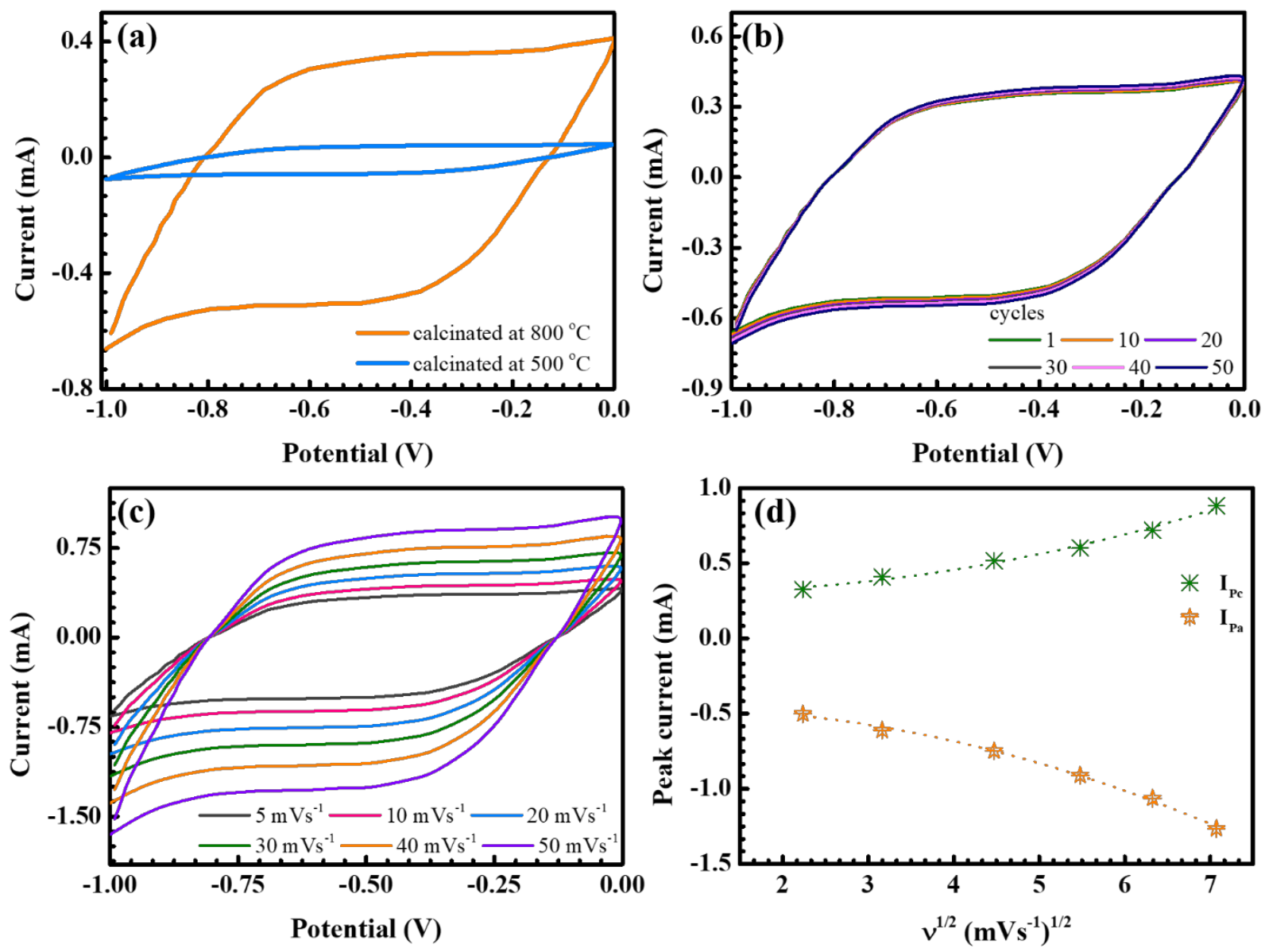

Figure 5: (a) CV curves for PNC, (b) CV curves for PNC recorded at different cycles, (c) CV curves recorded for PNC at different scan rates, and (d) peak current observed for PNC as a function of scan rate.

To evaluate the capacitive and charge transfer behaviors of the synthesized PNC, electrochemical impedance spectral analysis was performed; the registered complex impedance data are shown in Figure 6(f). The corresponding magnified region of the Nyquist plot for high frequencies is shown in the inset. Both of the Nyquist plots obtained for PNC before and after 
cycling consisted of two important regions: it behaved like a resistor in the maximum frequency (f) region and like a pristine capacitor in the lower $f$ region, i.e., the presence of a compressed semi-circle in the former region might be ascribed to the charge transfer resistance $\left(R_{\mathrm{CT}}\right)$ over the electrode electrolyte interface whereas the inclined spiky line in the latter corresponded to capacitor behavior. This phenomenon was further evaluated by an equivalent circuit fitting model using the Z-man software. Based on the fitted equivalent circuit model, it can be decided that the high $f$ non-zero intersection of the real $Z^{\prime}$ axis was related to the series resistance (ESR), which was a combination of the internal, ohmic, and interfacial resistances of the active electrode, the electrolyte, and interactions between the particles, respectively [67, 68]. The calculated ESR values for the fresh and post-cycling PNC-based cells were 1.34 and $1.91 \Omega$, respectively, which clearly indicated that there was no crucial change in the ESR value and therefore the prepared PNC was highly stable. Furthermore, the intermediate $f$ region of the plot exhibited a solitary compressed semicircle that may be accredited to the charge transfer resistance $\left(R_{\mathrm{CT}}\right)$ over the electrolyte electrode interface. The minor enhancement in the value of the $R_{\mathrm{CT}}$ after cycling (fresh cell: $2.7 \Omega$; after cycling: $3.7 \Omega$ ) may be due to lower ion transport, which in turn disturbed the conducting environment at the electrode-electrolyte interface. Additionally, the presence of an inclined spike line in the low $f$ range exhibited Warburg $\left(W_{\mathrm{R}}\right)$ resistance at angles of $45-90^{\circ}$, possibly on account of the electrolyte ions diffusion over the electrode-electrolyte interface. Lastly, a constant phase element, namely, the electric double layer capacitance $\left(\mathrm{CPE}_{\mathrm{dl}}\right)$, was included in the electric circuit to represent non-ideal performance. The values obtained for the parameter demonstrated the superior electrochemical behavior of the PNC electrode in combination with the electrolyte solution used. 

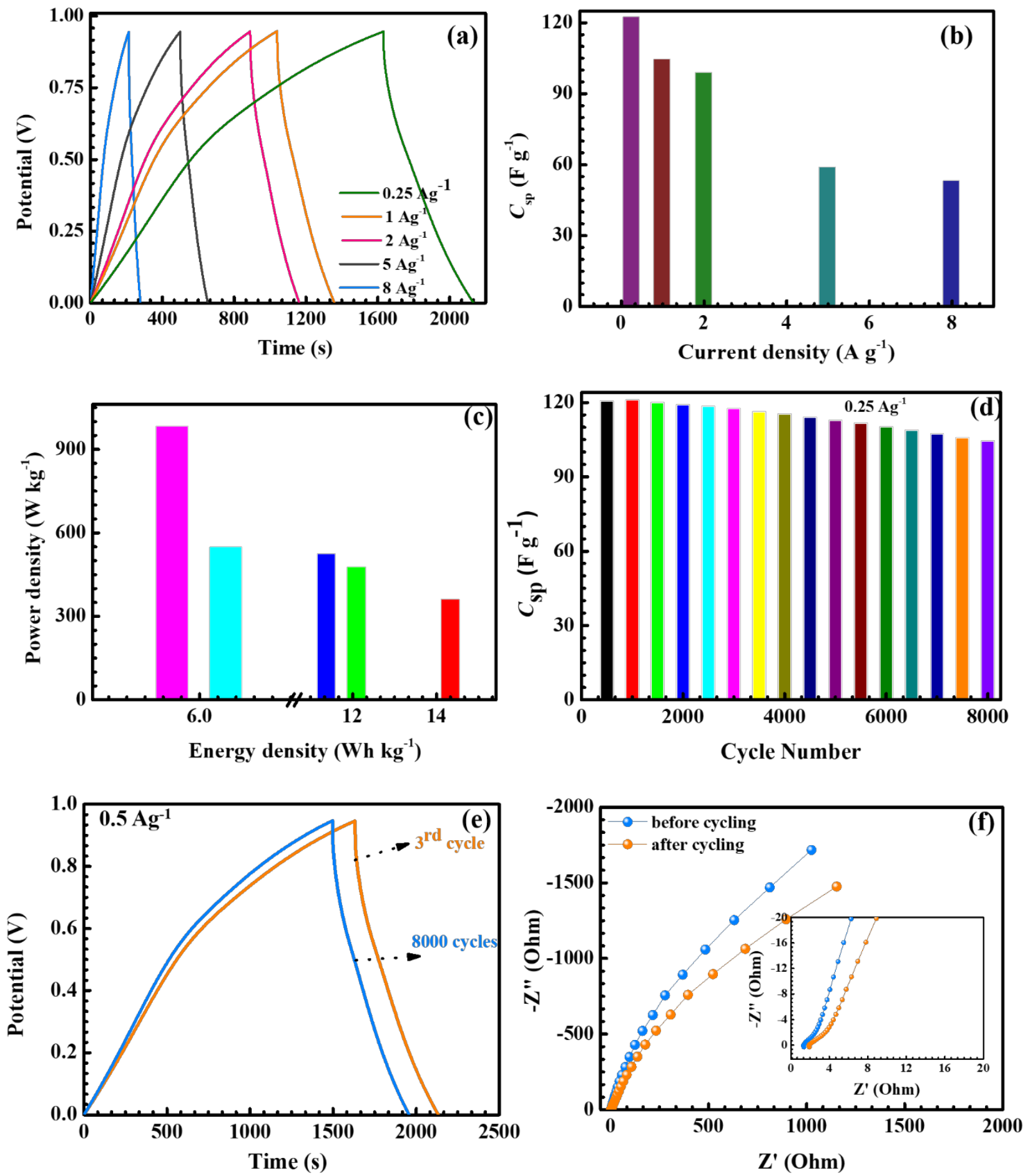

Figure 6: (a) GCD curves of PNC at different current rates of $0.25-8 \mathrm{Ag}^{-1}$, (b) $C_{\mathrm{sp}}$ vs current density rate, (c) PD vs ED, (d) evolution of specific capacitance of PNC over 8000 cycles, (e) 
GCD curves of PNC at initial and final cycles and (f) EIS of PNC (inset: enlarged image for the high-frequency region).

\section{Conclusions}

In summary, a porous nano-carbon (PNC) electrode was synthesized hydrothermally using a biopolymer phytagel and electrochemically evaluated for its application in solid-state supercapacitors. CV analyses of the PNC electrode showed a stability window of $1 \mathrm{~V}$ and demonstrated that it was electrochemically robust in the scanned potential range. Further, the PNC electrode exhibited $122 \mathrm{Fg}^{-1}$ as its highest specific capacitance at $0.25 \mathrm{Ag}^{-1}$ with outstanding capacity retention. The Ragone plot of the synthesized PNC electrode indicated energy densities 14.38 and $5.62 \mathrm{Wh} \mathrm{kg}^{-1}$ at a power densities of 360 and $980 \mathrm{Wkg}^{-1}$, respectively. The facile synthesis and improved capacitance behavior of the PNC electrode could lead to the progress of high-performance solid-state supercapacitor devices in the near future.

\section{Acknowledgements}

This work was partly supported by the Ministry of Trade, Industry and Energy (MOTIE, Korea) under Sensor Industrial Technology Innovation Program (No. 10063682), and the Basic Science Research Program through the National Research Foundation of Korea (NRF) funded by the Ministry of Education (No. 2017R1D1A1A09000823). One of the authors Dr. K.P. thankfully acknowledges European Union's Horizon 2020 research and innovation programme under the Marie Sklodowska-Curie grant agreement no. 713683 (COFUNDfellowsDTU) for their financial support. 


\section{References}

[1] P. Thounthong, S. Rael, B. Davat, Energy management of fuel cell/battery/supercapacitor hybrid power source for vehicle applications, Journal of Power Sources, 193 (2009) 376-385.

[2] C. Abbey, G. Joos, Supercapacitor energy storage for wind energy applications, IEEE transactions on Industry applications, 43 (2007) 769-776.

[3] E. Frackowiak, F. Beguin, Carbon materials for the electrochemical storage of energy in capacitors, Carbon, 39 (2001) 937-950.

[4] M. Sevilla, R. Mokaya, Energy storage applications of activated carbons: supercapacitors and hydrogen storage, Energy \& Environmental Science, 7 (2014) 1250-1280.

[5] L. Kouchachvili, W. Yaïci, E. Entchev, Hybrid battery/supercapacitor energy storage system for the electric vehicles, Journal of Power Sources, 374 (2018) 237-248.

[6] J.S. Lee, D.H. Shin, J. Jang, Polypyrrole-coated manganese dioxide with multiscale architectures for ultrahigh capacity energy storage, Energy \& Environmental Science, 8 (2015) 3030-3039.

[7] A.M. Abioye, F.N. Ani, Recent development in the production of activated carbon electrodes from agricultural waste biomass for supercapacitors: a review, Renewable and sustainable energy reviews, 52 (2015) 1282-1293.

[8] S. Ramesh, A. Kathalingam, K. Karuppasamy, H.-S. Kim, H.S. Kim, Nanostructured CuO/Co2O4@ nitrogen doped MWCNT hybrid composite electrode for high-performance supercapacitors, Composites Part B: Engineering, 166 (2019) 74-85.

[9] D. Vikraman, K. Karuppasamy, S. Hussain, A. Kathalingam, A. Sanmugam, J. Jung, H.-S. Kim, One-pot facile methodology to synthesize MoS2-graphene hybrid nanocomposites for supercapacitors with improved electrochemical capacitance, Composites Part B: Engineering, 161 (2019) 555-563.

[10] J. Theerthagiri, G. Durai, K. Karuppasamy, P. Arunachalam, V. Elakkiya, P. Kuppusami, T. Maiyalagan, H.-S. Kim, Recent Advances in 2-D Nanostructured Metal Nitrides, Carbides, and Phosphides Electrodes for Electrochemical Supercapacitors-A Brief Review, Journal of Industrial and Engineering Chemistry, (2018).

[11] M. Inagaki, H. Konno, O. Tanaike, Carbon materials for electrochemical capacitors, Journal of power sources, 195 (2010) 7880-7903. 
[12] R. Kötz, M. Carlen, Principles and applications of electrochemical capacitors, Electrochimica acta, 45 (2000) 2483-2498.

[13] C. Zhong, Y. Deng, W. Hu, J. Qiao, J. Zhang, Fundamentals of Electrochemical Supercapacitors, in: Electrolytes for Electrochemical Supercapacitors, CRC Press, 2016, pp. 1443.

[14] Y. Zhou, J. Ren, Y. Yang, Q. Zheng, J. Liao, F. Xie, W. Jie, D. Lin, Biomass-derived nitrogen and oxygen co-doped hierarchical porous carbon for high performance symmetric supercapacitor, Journal of Solid State Chemistry, 268 (2018) 149-158.

[15] A. Gopalakrishnan, S. Badhulika, Ultrathin graphene-like 2D porous carbon nanosheets and its excellent capacitance retention for supercapacitor, Journal of Industrial and Engineering Chemistry, 68 (2018) 257-266.

[16] R. Farzana, R. Rajarao, B.R. Bhat, V. Sahajwalla, Performance of an activated carbon supercapacitor electrode synthesised from waste Compact Discs (CDs), Journal of Industrial and Engineering Chemistry, 65 (2018) 387-396.

[17] I.I. Gurten Inal, S.M. Holmes, E. Yagmur, N. Ermumcu, A. Banford, Z. Aktas, The supercapacitor performance of hierarchical porous activated carbon electrodes synthesised from demineralised (waste) cumin plant by microwave pretreatment, Journal of Industrial and Engineering Chemistry, 61 (2018) 124-132.

[18] J. Chan Hyun, J.H. Kwak, Y.S. Yun, Microporous waste charcoals for redox-mediated supercapacitors, Journal of Industrial and Engineering Chemistry, (2019).

[19] J. Choi, N.R. Kim, H.-J. Jin, Y.S. Yun, Nanoporous pyropolymer nanosheets fabricated from renewable bio-resources for supercapacitors, Journal of Industrial and Engineering Chemistry, 43 (2016) 158-163.

[20] Y. Lian, M. Ni, Z. Huang, R. Chen, L. Zhou, W. Utetiwabo, W. Yang, Polyethylene waste carbons with a mesoporous network towards highly efficient supercapacitors, Chemical Engineering Journal, 366 (2019) 313-320.

[21] Y. Li, G. Wang, T. Wei, Z. Fan, P. Yan, Nitrogen and sulfur co-doped porous carbon nanosheets derived from willow catkin for supercapacitors, Nano Energy, 19 (2016) 165-175. [22] R. Xu, L. Xiao, L. Luo, Q. Yuan, D. Qin, G. Hu, W. Gan, Nitrogen, sulfur dual-doped mesoporous carbon modified glassy carbon electrode for simultaneous determination of hydroquinone and catechol, Journal of The Electrochemical Society, 163 (2016) B617-B623. 
[23] E.-A. Cho, S.-Y. Lee, S.-J. Park, Effect of microporosity on nitrogen-doped microporous carbons for electrode of supercapacitor, Carbon Lett, 15 (2014) 210-213.

[24] H. Yuan, L.-Y. Meng, S.-J. Park, A review: synthesis and applications of graphene/chitosan nanocomposites, Carbon Letters (Carbon Lett.), 17 (2016) 11-17.

[25] S. Lu, Y. Chen, J. Zhou, Z. Wang, X. Wu, J. Gu, X. Zhang, A. Pang, Z. Jiao, L. Jiang, A sheet-like carbon matrix hosted sulfur as cathode for high-performance lithium-sulfur batteries, Scientific reports, 6 (2016) 20445.

[26] C. Long, D. Qi, T. Wei, J. Yan, L. Jiang, Z. Fan, Nitrogen-doped carbon networks for high energy density supercapacitors derived from polyaniline coated bacterial cellulose, Advanced Functional Materials, 24 (2014) 3953-3961.

[27] Y. Zhai, Y. Dou, D. Zhao, P.F. Fulvio, R.T. Mayes, S. Dai, Carbon materials for chemical capacitive energy storage, Advanced materials, 23 (2011) 4828-4850.

[28] W. Du, X. Wang, X. Sun, J. Zhan, H. Zhang, X. Zhao, Nitrogen-doped hierarchical porous carbon using biomass-derived activated carbon/carbonized polyaniline composites for supercapacitor electrodes, Journal of Electroanalytical Chemistry, 827 (2018) 213-220.

[29] W. Zhang, H. Lin, Z. Lin, J. Yin, H. Lu, D. Liu, M. Zhao, 3 D Hierarchical Porous Carbon for Supercapacitors Prepared from Lignin through a Facile Template-Free Method, ChemSusChem, 8 (2015) 2114-2122.

[30] W. Zhang, J. Xu, D. Hou, J. Yin, D. Liu, Y. He, H. Lin, Hierarchical porous carbon prepared from biomass through a facile method for supercapacitor applications, Journal of colloid and interface science, 530 (2018) 338-344.

[31] D. Tang, Y. Luo, W. Lei, Q. Xiang, W. Ren, W. Song, K. Chen, J. Sun, Hierarchical porous carbon materials derived from waste lentinus edodes by a hybrid hydrothermal and molten salt process for supercapacitor applications, Applied Surface Science, 462 (2018) 862-871.

[32] Q. Wang, Q. Cao, X. Wang, B. Jing, H. Kuang, L. Zhou, A high-capacity carbon prepared from renewable chicken feather biopolymer for supercapacitors, Journal of Power Sources, 225 (2013) 101-107.

[33] W. Cui, N. Cheng, Q. Liu, C. Ge, A.M. Asiri, X. Sun, Mo2C nanoparticles decorated graphitic carbon sheets: biopolymer-derived solid-state synthesis and application as an efficient electrocatalyst for hydrogen generation, ACS Catalysis, 4 (2014) 2658-2661. 
[34] J. Wang, S. Kaskel, KOH activation of carbon-based materials for energy storage, Journal of Materials Chemistry, 22 (2012) 23710-23725.

[35] H. Chen, D. Liu, Z. Shen, B. Bao, S. Zhao, L. Wu, Functional biomass carbons with hierarchical porous structure for supercapacitor electrode materials, Electrochimica Acta, 180 (2015) 241-251.

[36] S. Senthilkumar, R.K. Selvan, N. Ponpandian, J. Melo, Y. Lee, Improved performance of electric double layer capacitor using redox additive (VO 2+/VO 2+) aqueous electrolyte, Journal of Materials Chemistry A, 1 (2013) 7913-7919.

[37] S. Ekici, G. Gungor, Investigation of the effect of laponite and crosslinkers on thermal, mechanical, swelling and conductive properties of the phtagel composite films, Smart Materials and Structures, 26 (2017) 035066.

[38] R. Singh, B. Bhattacharya, S. Tomar, V. Singh, P.K. Singh, Electrical, optical and electrophotochemical studies on agarose based biopolymer electrolyte towards dye sensitized solar cell application, Measurement, 102 (2017) 214-219.

[39] Y. Yang, J. Cui, M. Zheng, C. Hu, S. Tan, Y. Xiao, Q. Yang, Y. Liu, One-step synthesis of amino-functionalized fluorescent carbon nanoparticles by hydrothermal carbonization of chitosan, Chemical Communications, 48 (2012) 380-382.

[40] G. Fang, S. Kaneko, W. Liu, B. Xia, H. Sun, R. Zhang, J. Zheng, D. Li, Facile synthesis of nitrogen-doped carbon coated $\mathrm{CoSnO} 3$ via hydrothermal carbonization of carboxylated chitosan as anode materials for lithium-ion batteries, Applied Surface Science, 283 (2013) 963-967.

[41] T. Wu, G. Wang, X. Zhang, C. Chen, Y. Zhang, H. Zhao, Transforming chitosan into Ndoped graphitic carbon electrocatalysts, Chemical communications, 51 (2015) 1334-1337.

[42] A. Primo, E. Sánchez, J.M. Delgado, H. García, High-yield production of N-doped graphitic platelets by aqueous exfoliation of pyrolyzed chitosan, Carbon, 68 (2014) 777-783.

[43] A. Borenstein, O. Hanna, R. Attias, S. Luski, T. Brousse, D. Aurbach, Carbon-based composite materials for supercapacitor electrodes: a review, Journal of Materials Chemistry A, 5 (2017) 12653-12672.

[44] L.L. Zhang, X. Zhao, Carbon-based materials as supercapacitor electrodes, Chemical Society Reviews, 38 (2009) 2520-2531.

[45] H. Jiang, P.S. Lee, C. Li, 3D carbon based nanostructures for advanced supercapacitors, Energy \& Environmental Science, 6 (2013) 41-53. 
[46] D. Pech, M. Brunet, H. Durou, P. Huang, V. Mochalin, Y. Gogotsi, P.-L. Taberna, P. Simon, Ultrahigh-power micrometre-sized supercapacitors based on onion-like carbon, Nature nanotechnology, 5 (2010) 651.

[47] S. Bose, T. Kuila, A.K. Mishra, R. Rajasekar, N.H. Kim, J.H. Lee, Carbon-based nanostructured materials and their composites as supercapacitor electrodes, Journal of Materials Chemistry, 22 (2012) 767-784.

[48] J. Huang, J. Wang, C. Wang, H. Zhang, C. Lu, J. Wang, Hierarchical porous graphene carbon-based supercapacitors, Chemistry of Materials, 27 (2015) 2107-2113.

[49] E.J. Ra, E. Raymundo-Piñero, Y.H. Lee, F. Béguin, High power supercapacitors using polyacrylonitrile-based carbon nanofiber paper, Carbon, 47 (2009) 2984-2992.

[50] E. Raymundo-Piñero, F. Leroux, F. Béguin, A High-Performance Carbon for Supercapacitors Obtained by Carbonization of a Seaweed Biopolymer, Advanced Materials, 18 (2006) 1877-1882.

[51] E. Raymundo-Piñero, M. Cadek, M. Wachtler, F. Béguin, Carbon Nanotubes as Nanotexturing Agents for High Power Supercapacitors Based on Seaweed Carbons, ChemSusChem, 4 (2011) 943-949.

[52] P. Ratajczak, K. Jurewicz, F. Béguin, Factors contributing to ageing of high voltage carbon/carbon supercapacitors in salt aqueous electrolyte, Journal of Applied Electrochemistry, 44 (2014) 475-480.

[53] B.-H. Kim, K.S. Yang, H.-G. Woo, K. Oshida, Supercapacitor performance of porous carbon nanofiber composites prepared by electrospinning polymethylhydrosiloxane (PMHS)/polyacrylonitrile (PAN) blend solutions, Synthetic Metals, 161 (2011) 1211-1216.

[54] S. He, J. Cao, S. Xie, J. Deng, Q. Gao, L. Qiu, J. Zhang, L. Wang, Y. Hu, H. Peng, Stretchable supercapacitor based on a cellular structure, Journal of Materials Chemistry A, 4 (2016) 10124-10129.

[55] H. Xia, Y. Wang, J. Lin, L. Lu, Hydrothermal synthesis of MnO2/CNT nanocomposite with a CNT core/porous $\mathrm{MnO} 2$ sheath hierarchy architecture for supercapacitors, Nanoscale Research Letters, 7 (2012) 33.

[56] K. Yang, K. Cho, S. Kim, Effect of carbon black addition on thermal stability and capacitive performances of supercapacitors, Scientific Reports, 8 (2018) 11989. 
[57] N. Muralidharan, E. Teblum, A.S. Westover, D. Schauben, A. Itzhak, M. Muallem, G.D. Nessim, C.L. Pint, Carbon Nanotube Reinforced Structural Composite Supercapacitor, Scientific Reports, 8 (2018) 17662.

[58] H. Yu, K. Xie, J. Hu, C. Shen, J.-g. Wang, B. Wei, The importance of raw graphite size to the capacitive properties of graphene oxide, RSC Advances, 6 (2016) 17023-17028.

[59] G.A.M. Ali, S.A.B.A. Manaf, A. Kumar, K.F. Chong, G. Hegde, High performance supercapacitor using catalysis free porous carbon nanoparticles, Journal of Physics D: Applied Physics, 47 (2014) 495307.

[60] F. Razmjooei, K. Singh, T.H. Kang, N. Chaudhari, J. Yuan, J.-S. Yu, Urine to highly porous heteroatom-doped carbons for supercapacitor: A value added journey for human waste, Scientific Reports, 7 (2017) 10910.

[61] Y. Lu, S. Zhang, J. Yin, C. Bai, J. Zhang, Y. Li, Y. Yang, Z. Ge, M. Zhang, L. Wei, M. Ma, Y. Ma, Y. Chen, Mesoporous activated carbon materials with ultrahigh mesopore volume and effective specific surface area for high performance supercapacitors, Carbon, 124 (2017) 64-71.

[62] W. Sun, S.M. Lipka, C. Swartz, D. Williams, F. Yang, Hemp-derived activated carbons for supercapacitors, Carbon, 103 (2016) 181-192.

[63] F. Barzegar, J.K. Dangbegnon, A. Bello, D.Y. Momodu, A.T.C. Johnson, N. Manyala, Effect of conductive additives to gel electrolytes on activated carbon-based supercapacitors, AIP Advances, 5 (2015) 097171.

[64] G.A. Ferrero, A.B. Fuertes, M. Sevilla, From Soybean residue to advanced supercapacitors, Scientific Reports, 5 (2015) 16618.

[65] A. Śliwak, N. Díez, E. Miniach, G. Gryglewicz, Nitrogen-containing chitosan-based carbon as an electrode material for high-performance supercapacitors, Journal of Applied Electrochemistry, 46 (2016) 667-677.

[66] L. Gao, L. Xiong, D. Xu, J. Cai, L. Huang, J. Zhou, L. Zhang, Distinctive Construction of Chitin-Derived Hierarchically Porous Carbon Microspheres/Polyaniline for High-Rate Supercapacitors, ACS Applied Materials \& Interfaces, 10 (2018) 28918-28927.

[67] X. Deng, B. Zhao, L. Zhu, Z. Shao, Molten salt synthesis of nitrogen-doped carbon with hierarchical pore structures for use as high-performance electrodes in supercapacitors, Carbon, 93 (2015) 48-58. 
[68] Q. Liang, H. Su, J. Yan, C. Leung, S. Cao, D. Yuan, N-doped mesoporous carbon as a bifunctional material for oxygen reduction reaction and supercapacitors, Chinese Journal of Catalysis, 35 (2014) 1078-1083. 